\title{
Sociology and Science: The Making of a Social Scientific Method
}

\author{
Anson Au ${ }^{1}$ \\ Published online: 10 June 2017 \\ (C) The Author(s) 2017. This article is an open access publication
}

\begin{abstract}
Criticism against quantitative methods has grown in the context of "bigdata", charging an empirical, quantitative agenda with expanding to displace qualitative and theoretical approaches indispensable to the future of sociological research. Underscoring the strong convergences between the historical development of empiricism in the scientific method and the apparent turn to quantitative empiricism in sociology, this article uses content and hierarchical clustering analyses on the textual representations of journal articles from 1950 to 2010 to open dialogue on the epistemological issues of contemporary sociological research. In doing so, I push towards the conceptualization of a social scientific method, inspired by the scientific method from the philosophy of science and borne out of growing constructions of a systematically empirical representation among sociology articles. I articulate how this social scientific method is defined by three dimensions - empiricism, and theoretical and discursive compartmentalization -, and how, contrary to popular expectations, knowledge production consequently becomes independent of choice of research method, bound up instead in social constructions that divide its epistemological occurrence into two levels: (i) the way in which social reality is broken down into data, collected and analyzed, and (ii) the way in which this data is framed and made to recursively influence future sociological knowledge production. In this way, empiricism both mediates and is mediated by knowledge production not through the direct manipulation of method or theory use, but by redefining the ways in which methods are being labeled and knowledge framed, remembered, and interpreted.
\end{abstract}

Keywords Empiricism - Methodology Q Quantification · Knowledge production · Science Theory

Anson $\mathrm{Au}$

anson.au@alumni.lse.ac.uk

1 London School of Economics and Political Science, Department of Methodology, Columbia House, Houghton Street, London WC2A 2AE, UK 


\section{Introduction}

At the beginning of the twentieth century, American sociology began extracting itself from its theoretical and philosophical European influences in the development of the discipline as "an empirical and quantitative study" (Simmel 1950:xxiv-xxv), which then receded with the revived appeal of select European contributions during the midtwentieth century. ${ }^{1}$ Extending toward the late twentieth century, the rediscovered interest in theory was sustained and defined by the emergence of, and subsequent engagement with, wide-reaching social theoretical traditions that included Parsons' structural functionalism (Parsons 1937), social exchange theory by George Homans (1962) and Peter Blau (1967), conflict theory and its proponents among Lewis Coser (1956) and Ralf Dahrendorf (1959), phenomenology (Husserl 1965; Spiegelberg 196069), symbolic interactionism (Goffman 1959; Blumer 1962). The philosophical traditions and forms of thought represented in these paradigms have since, according to Gross (2007), disappeared from the face of sociology, its presence in the education and practice of sociology deemed dispensable for its treatment of the ideal (Bunge 1999; see also Riesch 2014), providing little more than a sense of intellectual and political purpose with its pragmatist progeny (Rucker 1969:162; Gross 2007).

But the battles over methodological and theoretical choices have returned (Babones 2016; Burrows and Savage 2014; Byrne 2012). In the March 2016 issue of the British Journal of Sociology, Swedberg (2016a), joined by a host of scholars, admonished against the marginalization of theory and its creation (theorizing) in sociological studies by methodological practice and education, and by extension, the empiricist tradition (see also Krause (2016), Bertilsson (2016)). Implicated is the failure of a theory construction movement and its formalized aspirations, displaced by grounded theory as a lukewarm attempt at reconstructing data; these efforts overburden induction, constituting a "bag of tricks" (Becker 1998, 2014) that offers little more than "a ritualistic nod towards the mandatory data analysis statement in a methods section" (Tavory 2016). Theorizing remains, within this camp, "not a methodology and... not a science... [but] a kind of pedagogy, and as such a branch of social theory" (Swedberg 2016b).

The propositions put forth, however, stand challenged by assertions that theorizing is actually commonplace (Abbott 2012), grounded on claims that the standards with which to evaluate theoretical productions are localized (in what may be called "generational paradigms") ${ }^{2}$; in other words, the isolated but concurrent development of disparate research agendas across communities suggest a severely fragmented enterprise of social scientific theory construction impossible to overcome (Abbott 2001). These debates on

\footnotetext{
${ }^{1}$ Notable among which were Talcott Parsons' The Structure of Social Action (1937) and new English translations of Max Weber. Talcott Parsons, The Structure of Social Action, a Study in Social Theory with Special Reference to a Group of Recent European Writers [Durkheim, Pareto, M. Weber], New York and London: McGraw-Hill, 1937 (reprinted, Glencoe, 111.: Free Press, 1949). Max Weber, The Protestant Ethic and the Spirit of Capitalism, tr. Talcott Parsons, London: Allen and Unwin; New York: Scribner, 1930; From Max Weber: Essays in Sociology; The Theory of Social and Economic Organization, tr. A. M. Henderson and Talcott Parsons, New York: Oxford University Press, 1947; On the Methodology of the Social Sciences, tr. and ed. Edward A. Shils and Henry A. Finch, Glencoe, 111.: Free Press, 1949.

2 Abbott (2001) refers to these pockets of research communities as "generational paradigms", or "cumulating little programs of social science in which this or that group is rediscovering some important truth in a disciplined and corporate way" (as cited in Abbott (2012))
} 
quantification arise simultaneously with recent linguistic and psychological research that identify greater attention to causal connections in education, technology, and science in Western societies throughout the twentieth century (Iliev and Axelrod 2016); reflected is a changed form of culture that motivates causality in psychological cognition (Penn and Povinelli 2007), as operationalized through causal attribution and causal judgments (Norenzayan and Nisbett 2000).

That these conflicts on quantification are fundamentally aligned across multiple dimensions of methodology, theory, and discourse gives credence to how the implications of methodology extend beyond itself to affect issues of theory and, ultimately, the "scientific development" of sociology (Horowitz 1994:22). Against this backdrop, this article aims to evaluate claims against empiricism by schematically measuring the convergences and divergences of the development of sociological methods against those of the scientific method in the philosophy of science. Doing so unearths the extent to which a "social scientific method" - a privileged mode of knowledge production - is emerging in the sociological discipline, like that among the natural sciences. Moreover, by gleaning insights from the history and philosophy of science, we can further uncover and assess the future trajectories of sociological knowledge production. Content and hierarchical clustering analyses were applied on abstracts and titles of journal articles from 1950 to 2010 to ascertain changes in the discursive constructions used to frame and represent sociology. I will use these preliminary analyses to open dialogue on a set of preoccupations concerned about the development of a social scientific method, measured against the scientific method.

\section{The Development of the Scientific Method}

\section{Historical Preliminaries}

What is the nature of science? The answer has changed from time to time. Surveying the development of scientific methods across history, four phases emerge in historical investigations of the nature of science (Hoyningen-Huene 2008):

1. From Plato to the seventeenth century: the distinction between episteme and doxa (belief), of which the former was irrevocable science.

2. From the seventeenth century to the nineteenth century: the inclusion of inductive practices in a set of procedures labelled "scientific methods", grounded on the stillunshakable certainty of scientific knowledge;

3. From the mid-nineteenth century to late twentieth century: empirical data produced by "scientific methods" are recognized as fallible, though still afforded a "special" or privileged status;

4. From the late twentieth century to present: the dissolution of consensus concerning the nature of science, and of belief in the scientific method as a "special" mode of knowledge production (Hoyningen-Huene 2008).

Presently, there is little consensus among philosophers, historians, or scientists about the specific nature of science, but their debates converge on accepting the "specialness" 
of science that distinguish it from alternate forms of knowledge, and which are organized around systematicity. Taking this as a point of departure, historical assessments have consistently articulated eight dimensions of this systematicity, the combination of which were taken to consist the definition of science: descriptions, explanations, predictions, defense of knowledge claims, epistemic connectedness, ideal of completeness, knowledge generation, and representation of knowledge.

\section{Progressing Through the Phases: Intellectual Movements}

What drives progression through these phases? To find an answer, we should turn to how intellectual paradigm shifts are generated. Drawing from general scientific/ intellectual movements (SIM) theory (Frickel and Gross 2005), the factors driving scientific movement and changes in intellectual paradigms consist of: (i) a coherent program for intellectual advancement, transforming thought and affecting knowledge circulation; (ii) resistance against norms; (iii) contention arises within intellectual fields in political contest with what appears to be an unequal distribution of power (Bourdieu 1988), from which emerges (iv) collective actions of resistance in the forms of scholarly publications; (v) variation in the aims and scope of quantified empiricism across disparate subdisciplines/topics; (v) and whether these trends are episodic.

Table 1 illustrates how empiricism within sociological forms of knowledge aligns with these criteria, giving credence to the symmetry between the two histories of scientific methods. Whilst the dimensions of systematicity are present in the development of sociological praxis, what qualities may be unique to sociology? Against these backdrops, which phase has sociological knowledge progressed to? Have quantitative, empirical methods truly become a "special" or standard mode of production? How have the representations adopted by American sociology changed, within its supposed quantitative shift?

Table 1 Empiricism in sociological knowledge compared against SIM characteristics

\begin{tabular}{|c|c|c|}
\hline & Empiricism & SIM characteristics \\
\hline (i) & $\begin{array}{l}\text { Empiricism prescribes specific methodological foci rooted } \\
\text { in scientificity for how to best study sociology and to } \\
\text { advance the discipline (Hanson 2008). }\end{array}$ & $\begin{array}{l}\text { Coherent program for scientific } \\
\text { advancement. }\end{array}$ \\
\hline (ii) & $\begin{array}{l}\text { Empirical and quantitative ideas and methods resisted } \\
\text { against the predominance of social theoretical } \\
\text { traditions, empowering positivism (Goode 1960). }\end{array}$ & $\begin{array}{l}\text { Core of intellectual practices contend against } \\
\text { normative expectations. }\end{array}$ \\
\hline (iii) & $\begin{array}{l}\text { Statistical analysis grew to fuel professionalization across } \\
\text { disciplines, and altered and proliferated in policy } \\
\text { groups and think-tanks (Howard 1981:98). }\end{array}$ & Alter distributions of power and resources. \\
\hline (iv) & $\begin{array}{l}\text { General growth in the number of scholarly publications } \\
\text { with statistical methods (Burrows and Savage 2014) } \\
\text { and journals dedicated to quantitative approaches. }\end{array}$ & $\begin{array}{l}\text { Collective actions that spread particular } \\
\text { ideas in intellectual networks. }\end{array}$ \\
\hline (v) & $\begin{array}{l}\text { Variation in the scope of quantified empiricism across } \\
\text { disparate subdisciplines/topics, including } \\
\text { statistical methodology. }\end{array}$ & $\begin{array}{l}\text { Vary in intellectual aim and scope, with new } \\
\text { methods and rule-making procedures. }\end{array}$ \\
\hline
\end{tabular}




\section{Data and Methods}

\section{Sample}

The criteria for selecting journals were guided by the qualities of having a high impact factor, to ensure the journals' representation of major interests among contemporary American sociology given its importance in the American social sciences (Adkins and Budd 2006; Jacobs 2011, 2016), and general thematic interests, in principle open to the publication of all topics without overt bias. Keeping this in mind, the American Journal of Sociology, the American Sociological Review, and Social Forces were selected to best ensure that any trends identified actually reflect voluntarily decided interests among American sociologists from 1950 - the heyday of American sociology - to 2010.

\section{Sampling}

Sampling occurred in two phases, using a systematic sampling procedure, contrary to random sampling. Whereas the latter is most appropriate for detecting collective patterns within a single, homogeneous corpus of texts, the ability to trace developments of these patterns longitudinally across heterogeneous periods remains accessible only by a systematic sampling over the period of interest, lost to random sampling. The first phase incorporated the selection of articles from all issues of a single year for every ten years from 1950 to 2010. Sampling and recording units converged in their definition of journal articles as thematic or semantic units (Krippendorff 1980:61ff). The American Journal of Sociology publishes six issues per year, with six to seven articles in each issue, for a total of 283 articles; the American Sociological Review published six issues per year, with eight articles in each issue, for a total of 223 articles; Social Forces publishes four issues a year, with seventeen articles in each issue, ${ }^{3}$ for a total of 288 articles. From the seven rounds of selection between 1950 and 2010, the total corpus of recording units amounted to 794 journal articles. The second phase of selection involved systematically selecting every fifth article from a randomly selected start amongst the lists of articles for each journal. The American Journal of Sociology produced a sample of 58 articles, the American Sociological Review produced a sample of 66 articles, and Social Forces produced a sample of 58 articles. The final, total sample thus amounted to 182 articles $(n=182)$.

\section{Methods}

The articles were imported into QDA Miner and content analysis was performed using Wordstat, enabling a thematic analysis to be conducted using all titles and abstracts from the corpus of texts. Titles and abstracts were chosen, as they best captured the matter of representation; body texts would not have tapped into this dimension sufficiently. Content analysis systematically and publicly manipulates large amounts of naturally

\footnotetext{
${ }^{3}$ Social Forces only started publishing from 1974 onwards. However, the paucity of articles from 1950 to 1960 are partially accounted for by the journal's more extensive publishing schedule (it publishes more articles per year than the other two journals).
} 
occurring materials to construct historical data (Bauer 2001:147). By producing collective-level data, it leaves enough room for interpretation to uncover social trends among representations presented by the materials (ibid:133). Two functions of content analysis best accommodate it to the research agenda: (1) constructing a text corpus as an open system by continuously adding texts to capture the recent progression of methodological trends; and (2) the construction of indices, to describe an index of the social and philosophical values behind the methods of choice (Krippendorff 1980). Given the significance of journal articles in American sociology (Cronin et al. 1997) and their status as texts produced for an alternate purpose (Bauer 2001:136), they were selected as the recording units for my collection of textual data. They most accessibly allow for diagnosis and assessment the interests of the discipline as texts available in digital archives within institutional libraries and respective journal webpages, proffering opportunities to analyze historical perspectives and developments, otherwise unavailable to participant data collection tools. Furthermore, this tests the hypothesis that the representation of sociology is tending towards empiricist, systematic frames by illuminating the discourse used to frame articles as knowledge productions.

Frequency analysis and hierarchical clustering techniques were then used to inductively explore the themes embedded from the dataset. Subsequently, I created a categorization dictionary that grouped the text according to five major themes: (1) examination and measurement; (2) structure and function; (3) analyses, evidence, hypotheses; (4) external reference; and (5) system (see Appendix for further information on these dictionaries).

\section{Structured Ways of Measurement and Analysis}

A content analysis for word appearances was conducted using title and abstract data from the sample. In Wordstat, the results of the initial analysis were filtered by removing words that fell under at least one of two categories: (i) words pertinent to substantial or topical issues in the articles (i.e. "power", "gender", etc.); and (ii) "leftover" words with very small frequencies (fewer than ten appearances). Following this initial sweep, 60 words ${ }^{4}$ remained that were directly pertinent to the dimensions of systematicity in the philosophy of science, with frequencies that ranged from 72 appearances in 53 cases ("research") to 10 appearances in 2 cases ("matching"). That is, all the remaining words gravitated towards aspects of measurement, systems, evidence, examination, analysis, prediction, and connectedness to external bodies of work.

Figure 1 compares the frequencies of the top fifteen most used words by year (see Appendix for descriptive frequencies and for full dictionary of the 60 words). ${ }^{5}$ Six of the words - "research", "data", "study", "analysis", "findings", "differences" - were used from 1950 or prior; another six - "theory", "effects", "support", "structure",

\footnotetext{
${ }^{4}$ The 60 keywords included in Fig. 1 essentially consist of words that deal with aspects of "methodology", rather than the entire corpus of keywords $(n>200)$; the 60 keywords was consistent with the hierarchical clustering in Fig. 3, which grouped them into thematic clusters within "methodology".

${ }^{5}$ Rather than conducting a coding frequency for all the words from top cluster in the hierarchical clustering analysis ("analyses, evidence, hypotheses"), which would've appeared difficult to interpret and analyze with 34 diagrams to follow.
} 
Total Frequency for YEAR (Column percent)

\begin{tabular}{|c|c|c|c|c|c|c|c|c|c|c|c|c|c|c|c|}
\hline & 哭 & $\underset{\mathrm{g}}{\mathrm{g}}$ & $\underset{\mathrm{g}}{\mathrm{g}}$ & $\underset{\mathrm{g}}{\stackrel{\circ}{\circ}}$ & 兽 & 言 & 올 & & 哭 & $\underset{\%}{\stackrel{\circ}{\sigma}}$ & $\underset{\%}{\stackrel{9}{\sigma}}$ & $\underset{\mathrm{g}}{\stackrel{\mathrm{g}}{\mathrm{F}}}$ & 奇 & ్ㅡㅁ & 울 \\
\hline RESEARCH & & & & & & & & SUPPORT & & & 0 & 0 & & & \\
\hline DATA & & & & & & & & STRUCTURE & & & 0 & 0 & & & 0 \\
\hline STUDY & & & & & 0 & & & RESULTS & & & 0 & 0 & & & \\
\hline THEORY & & & & & & O & & DIFFERENCES & 0 & 0 & 0 & 0 & & & 0 \\
\hline ANALYSIS & & 0 & & & & & & SYSTEM & & & 0 & 0 & 0 & 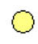 & \\
\hline EFFECTS & & & 0 & 0 & & & & RATES & & & 0 & 0 & & & 0 \\
\hline MODEL & & & & & 0 & & $\mathrm{O}$ & EFFECT & & 0 & 0 & 0 & & 0 & \\
\hline FINDINGS & & & & & 0 & & & & & & & & & & \\
\hline
\end{tabular}

Fig. 1 Coding frequency of the top fifteen words of use (pertaining to aspects of measurement, system, evidence, etc.) among articles by year (compares their frequencies and their relative distribution over time)

"system", "effect" - were only used by 1960; and the remaining three - "model", "results", "rates" - by 1970. Almost all words have declined in frequency since 1950, most notable among them "analysis", whose frequency dropped from $15.79 \%$ among the 60 words in 1950 to $2.96 \%$ by 2010 (see Table 2 in Appendix).

Throughout 1950 to 2010, use of the words "research", "data", "study" have remained steady or returned to their former high frequencies, indicating the consistency of empiricism as a mode of representing sociological articles. The organization of abstracts demonstrated compartmentalization into the description of a research question or inquiry, followed by research data and method used in its exploration, and the main results summarized. In one study of Vatican voting politics, for instance, the authors preface their abstract by noting they "explore the national factors that predict bishops' votes on two of the most contentious issues at the Second Vatican Council". They then identify their data source as the "Vatican Secret Archive," after which "analyses [demonstrated] that rational choice oriented theory in the sociology of religion that focuses on competition is limited" (Wilde et al. 2010).

Comparing this with two earlier articles, also investigating the sociology of religion in the same journal, ${ }^{6}$ helps illuminate the conditions of empiricism's function as a discursive framing mechanism, contingent on use of methodology rather than time period. All three elements in the same compartmentalization was observed in an empirical study of Catholicism written in 1960, where its abstract demonstrated its inquiry, data source and methods, as well as results in a comparable order: "in an urban community in northern Florida patterns of social integration among Catholic migrants were analyzed. Seven sets of attitudinal scales were constructed, and the area of value integration was compared with patterns of social participation and degrees of identification with the South. It was found that manifestation of attitudinal inconsistency seemed to have been distinctive of the 'high' Catholicity group rather than of the 'low.'" (Liu 1960).

\footnotetext{
${ }^{6}$ The American Journal of Sociology.
} 
Continuing with this example, in the abstract of a non-empirical (theoretical) study of Judaism in 1960, no references were made to methodology. Intriguingly, the compartmentalization observed in the other abstracts, despite their common subtopic, was absent, delving principally into the iteration of results (Wax 1960). But that the majority of the most frequently used words selected have declined over time also suggests the concurrent adoption of alternate discursive constructions. In particular, discursive frames being used are constructed based on words not captured or related to aspects of measurement, systems, evidence, examination, analysis, prediction, or connectedness to external bodies of work through references. Two possibilities arise in the attempt to understand these frames, drawing reference from the themes initially filtered out: (i) "leftover" words with very small frequencies (fewer than ten appearances). As a result, content (frequency) analysis would offer limited assistance beyond sensitizing scholars to the extent to which this is the case, given the sheer volume of "leftover words"; (ii) Word usage has shifted to encompass substantial or topical issues. Figure 2, comprised of the most used topical words from the unfiltered corpus of keywords, ${ }^{7}$ provides some evidence of this, indicated by the growth and frequencies of certain topical words superior to those of words from Fig. 1, such as "social", "political", and "organizational"; (iii) the diversification of interests, wherein topics and words to describe them are generated by an expanding scope of sociological inquiry.

\section{Empiricist Frames and the Use of Concepts}

Hierarchical clustering was used to uncover clusters generated from co-occurrences of the most common words or phrases, taken to construe topics or themes in the data. Seven clusters were generated, ${ }^{8}$ but two were removed as a result of low word counts (full categorization dictionary in Table 3 under the Appendix). ${ }^{9}$ Comparing these results with the fifteen words from Fig. 1, thirteen were from the "analyses, evidence, hypotheses" theme, while the remaining two were from the "system" theme (see Table 3).

Figure 3 shows the relative weight of each of the five themes over time. It also shows the consistency with which "analyses, evidence, hypotheses" were used and acquired prominence over the other four themes ("examination and measurement", "structure and function", "external reference", and "system"). Empiricism as a discursive frame gains credence from the growing frequency of words along the lines of "analyses", "evidence", "hypotheses" - closely aligning with the systematic elements of compartmentalization (inquiry, data and analysis, results) observed with the vocabulary frequency analysis. Thus,

\footnotetext{
${ }^{7}$ Figure 2 needed to draw from an unfiltered corpus of keywords in order to obtain topical keywords.

${ }^{8}$ Any higher number of clusters did not stratify "analyses, evidence, hypotheses", the largest cluster. For instance, this cluster consisted of 39 words at seven clusters; increasing the number of clusters (to eight) only shrunk the other clusters; conversely, reducing the number of clusters (to six) added to the size of this cluster. Seven clusters thus provided the smallest difference in size or the most even distribution of size among the clusters.

${ }^{9}$ Clusters with only one word in them were removed.
} 
Total Frequency for YEAR

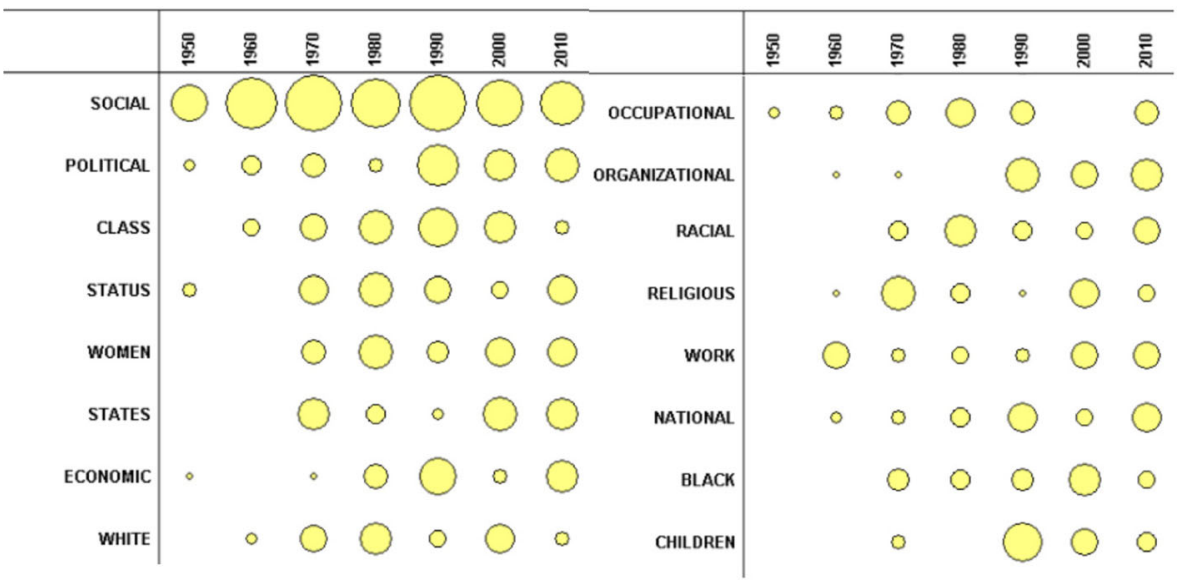

Fig. 2 Coding frequency of top sixteen words of use (pertaining to topics) among articles by year. 16, rather than 15 to match Fig. 1, for the fact that "black" and "children" share identical frequencies

Fig. 3 also further illustrates the persistence of compartmentalization among representations of sociology across time.

These results resonate with the historical turn away from theory, but also illuminates where it stands today: in the wake of the disappearance of big-theory or theoretical thinking (Swedberg 2016a, b), a new "micro-theory" emerged; a novel means of doing theory, micro-theory refers to thinking in terms of concepts, and the intellectual means by which these concepts are constructed. Systems of thought are parceled into concepts, which are then extracted to be applied within increasingly localized problems and studies (Ivinson et al. 2011).

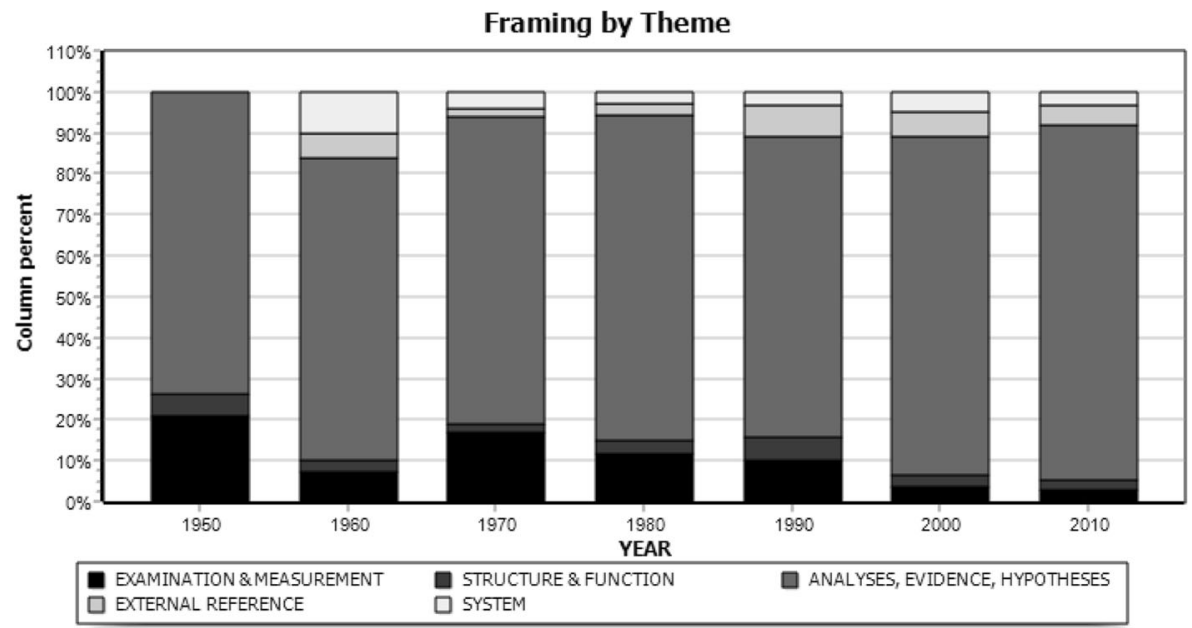

Fig. 3 Framing of articles by thematic clusters (shows the relative weight of each of the five clusters over time across all journals) 


\section{Constructing Social Representations: Empiricism and Systematicity in Sociology}

Communication scholars assert that there is no such thing as bias - only the construction of representations. Whilst the content and hierarchical analyses' results help to better contextualize contemporary debates on the development and trajectory of sociological ways of knowing by illuminating the representations of a quantitative, empirical method in journal articles, a theoretical approach is required to make sense of these representations in broader epistemological changes within the discipline. Keeping this in mind, social representations theory helps unpack the ways in which this process works.

Representation, according to Bauer and Gaskell (1999), is embodied in both communication and in individual minds, comprising of three elements: subjects conducting the representation, the represented object, and the project from which the representation draws its context. Subjects $(\mathrm{S})$ are theorized to interact in ways that give shape to an object $(\mathrm{O})$, a process which, over time, accumulates into a project $(\mathrm{P})$ with a direction. Mediating between this triadic relationship and the dimension of temporality renders visible a "toblerone" model (Fig. 4).

The structure of representations negotiated between subjects and objects is rooted in the processes of anchoring, the classification of novel ideas/things, and objectification, the reification of ideas (Moscovici 1984); all occur through the distribution and exchange of images, exemplars, and models, constituting the empirical data for studying social representations (Bauer and Gaskell 1999). Specific to the question of how sociology represents itself, mediums of representation include the words and terms with which published research is described, while modes of representation deal principally with habitual practices, operationalized as how research is framed.

Social representations theory offers a distinct approach to depict the discursive constructions (or the representation) of sociology, and ultimately drawing connections between elements in their structure and the dynamics of a broader project. For this reason, the epistemological trends in sociological knowledge production can be

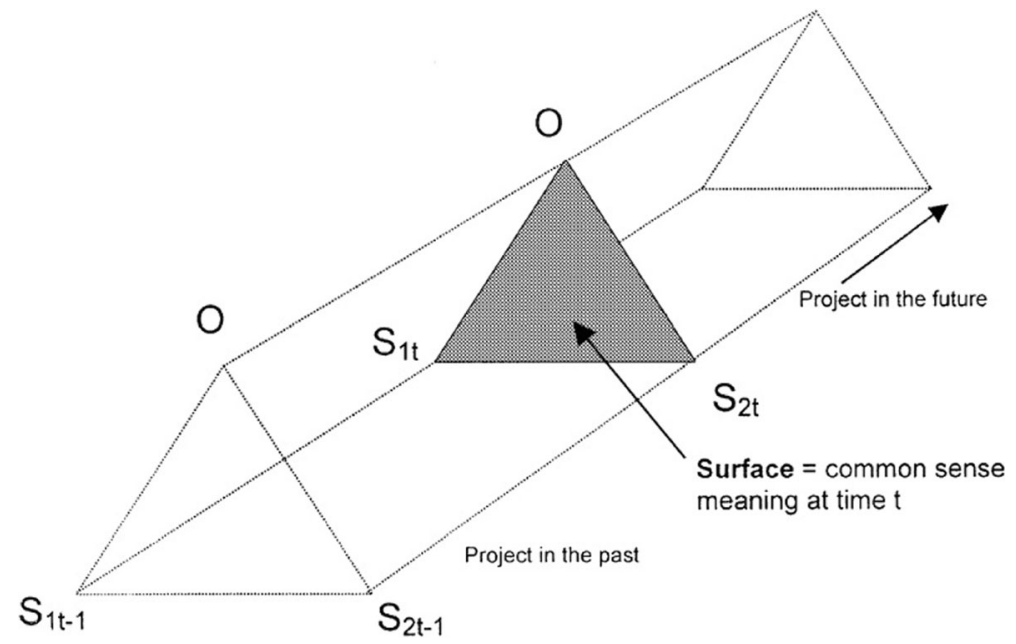

Fig. 4 The "toblerone" model of social representations (Bauer and Gaskell 1999) 
conceptualized as the mobile project $(\mathrm{P})$ within the toblerone model of social representations. Unearthing the contexts of sociology's representational project $(\mathrm{P})$ would shed light on the repertoire of assumptions that motivate and organize sociological research practice (Bauer and Gaskell 2008), ultimately excavating the determinants and directions of collective activity within the discipline (Israel and Tajfel 1972).

Where individual authors/articles would be conceptualized as subjects (S) in the toblerone model of social representations (Bauer and Gaskell 1999), the ways in which words are used constitutes the mediation process by which a more abstract object $(\mathrm{O})$ is established between the subjects. The rising eminence of words redolent of "analyses", "evidence", "hypotheses" - closely aligning with the systematic elements of compartmentalization (inquiry, data and analysis, results) observed with the vocabulary frequency analysis points to how systematic empiricism was the discursive frame constructed, an abstract object $(\mathrm{O})$ emergent from mediation between articles $(\mathrm{S})$ using words.

Taking systematic empiricism to comprise the abstract object (O), its adherent conditions and changes can be mapped onto a larger project concerning the representation of sociology as a discipline (P). That the popularity of empiricism as a discursive frame in American sociology is consistent throughout time indicates that the ways in which research is framed is, in part, independent of choice of method. This finding runs counter to the claims admonishing against the displacement of non-empirical, quantitative ways of knowing. It urges the separation of the resistance for theory and the resistance for qualitative methods, whose lines of inquiry are often entangled: articles applying qualitative methods play a part in recreating the empiricist frame with which quantitative-based articles are constructed. We observe the cessation of more and more ground to through the processes of compartmentalization in theoretical terms - the growing use concepts as micro-theory - and in discursive terms - framing even qualitative results according to the same empiricist traditions. Mapping these trends into the future of the representation of sociology, they lend partial corroboration to speculations of how the proclivity towards empiricism as a mode of construction (Iliev and Axelrod 2016), and a substitute for dialogue (qualitative descriptions).

\section{The Making of a Social Scientific Method}

\section{The Development of Sociological Methods in their Historical Context}

Scholars have made note of how, from the mid-1960s, diversions from theory (Calhoun 2007; Platt 1996) were compounded by the apparent disillusionment with Marx under accusations of economic reductionism (Zeitlin 1973:110) in reproducing an empiricist fervor with quantitatively methodological overtones that was nurtured by increasingly bureaucratized and specialized institutions (Howard 1981:3; Zeitlin 2001:234), and professionalized disciplines within American social science (Goode 1960). The beginnings of these changes are commonly attributed to influxes of federal and private funding during and following World War II (Kleinman 1995; Price 2003; Turner and Turner 1990). But more than the obligations imposed by material resources in shaping sociologists' epistemological orientations, it was the "Fordist forms of societal regulation [that] resonated powerfully with social science positivism" that encouraged 
"the epistemic realignment in sociology by making positivism seem more plausible... Fordism as a mode of social regulation insisted on the ontological reality of 'the social' as an object, and... as a result, sociologists were especially fixated on the predictable, repeated regularities of social existence inside the U.S. metropole." (Steinmetz 2007)

Implicated is a demand for statistical analysis in servitude of administrative purposes and to constitute the basis for rational, precise, real decision-making in American sociology (Howard 1981:98). That the bureaucratic restructuring of institutions according to hierarchical, rigid standards is irreversible (Zeitlin 2001:236) and that social research activity organized around quantitative methodology, increasingly intersected with computer science, has proliferated in social policy groups and think-tanks indicate that this new form of rationality still persists.

Though sociology as an institutionalized, distinct discipline is far shorter lived than its scientific counterpart, we can nevertheless measure these observations in historiographic scholarship against the schematic evolution of the scientific method to give shape to the following phases in sociological development:

1. Pre-WWII: methodological pluralism in which qualitative and theory played a stronger role than quantitative methods.

2. From WWII to 1960s: the proliferation of statistics as they begin to become the epicenter of sociological inquiry.

3. From the 1960 s to present: the displacement of theory and non-quantitatively empirical methods by quantitative methods as they become a "special" mode of knowledge production.

The content and hierarchical clustering analyses' results further refine this picture by revealing important distinctions. The sense of infallibility that defined the early phases of scientific development is absent in sociology. It is more common for empirical results to be questioned on the grounds of context and positionality, for instance. But are quantitative methods imbued with a "special" or privileged status? Evidence suggests that quantitative methods have grown to become the predominant mode of knowledge production in American sociology (Au and Bauer 2017). The results here supplement this conclusion by altering the foundation of the question: what we observe is not just a common method being used, but a common method that is being constructed. That is, the diversity of methods used over the past half century converge upon a common approach, evinced by the identical ways in which sociological knowledge is framed and representations of social reality constructed.

But in hindsight, on account of the persistence of these trends throughout the years, it was not Fordism that drove them. So what did? Corroborating yet splitting from scholars on quantitative, qualitative, and theoretical sides of the debates, the picture of sociological knowledge production being painted here is more complex than suggested by any side. We can observe how knowledge production is epistemologically occurring on two levels: (i) the way in which social reality is broken down into data, collected and analyzed, and (ii) the way in which this data is framed, and made to recursively influence future sociological knowledge production. Whilst there is no single technique or method that takes precedence in (i), such as regressions, linear models, etc. (ibid), the evidence 
suggests that the production of knowledge and the application of these techniques, diverse as they are, is being credited to the same approach. Thus, empiricism both mediates and is mediated by knowledge production not through the direct manipulation of method or even theory use, but by redefining the ways in which methods are being labeled and knowledge framed and remembered. In this way, systematic empiricism is the approach, not method, of knowledge production that becomes too embedded in American social scientific conduct to be displaced (White 1998).

\section{Tenets of Sociological Systematicity}

Just as the concept of systematicity bound together all the disparate definitions of the scientific method in a set of dimensions, what are the dimensions that constitute the social scientific method or the approach of systematic empiricism? The results identify dimensions of the scientific systematicity within this approach. Despite the fact that frequencies of words pertaining to models and measurement (Fig. 1) have individually decreased, there are collectively more of them in usage by 2010: a surge in new words around 1960-1970 coincides with a drastic rise several indicators of scientificity, lending some empirical corroboration to hitherto theoretical attributions of quantification to a 1960s Fordist rationale, which shares many characteristics with quantified, systematized scientificity (Steinmetz 2007). Indeed, imagined as a project (P) extended over time, the representation of sociology continues its subjection to an empiricist (object $(\mathrm{O})$ ) discursive frame, converging with its propulsion towards an increasingly systematized and rigidized standard of knowledge production and communication seeking to "imitate the quantifying methods and opaque idiom of the hard sciences" (Nisbet 2002[1976]:xi).

But whilst the dimensions of scientific systematicity are present in the development of sociological praxis (Au and Bauer 2017), what additional qualities of a social scientific method exist that are unique to social science? Or rather, what distinguishes systematic empiricism from the scientific concept of systematicity? Perusing the analyses' results, several articulations are possible:

1. Empiricism: using methods to explore social reality through measurement. Unlike science, social science carries a tradition of using theory to interpret reality; the point of contact between reality and ourselves is intrapersonal. By approaching the quest to uncovering knowledge with measurement, the contact between researcher and reality becomes pushed outside ourselves. It does not matter how we explore social reality, so long as it can be broken down into data and demonstrated to be measurable and outside ourselves.

2. Discursive compartmentalization: reorganizing the body of a scholarly production to comply with a structured form. The order forced upon the presentation of knowledge not only represents an attempt to make it relatable and legitimized, but simultaneously reorganizes the way knowledge is understood - social reality becomes structured and breakable in ways beyond the article, rigidizing our ways of knowing, of remembering, and of interpreting.

3. Theoretical compartmentalization: breaking apart systems of thought into smaller concepts, which are extracted from their original context to be applied to other 
contexts and research problems. The widely held imperative for generalizability best evinces and motivates the latter two dimensions, representing a bid to connect researchers to others, and localized knowledge to larger currents of research.

\section{Discussion}

In response to expansion of Big Data (Benoit 2015), moral panics have erupted between embattled qualitative/theoretical and quantitative camps over the future of sociological research and methods deemed external to an empirical, quantitative agenda. Strong convergences are drawn between this apparent recent turn to quantitative empiricism in sociology and empiricism in the historical development of the scientific method. Keeping this in mind, this article scopes the extent to which these claims made against an encroaching quantitative empiricism are true by comparing the discursive constructions employed by mainstream sociologists with the development of science, ultimately pushing towards a more complex conceptualization of empiricism and epistemology. A key result concerns the systematic framing of articles that even qualitatively grounded studies endorse, urging scholars to grow more sensitized not only to the distinction between the often enjoined qualitative and theoretical camps in their battle against quantification, but also to the differentiation of two levels in knowledge production: analysis, and construction.

Surveying this construction, content and hierarchical analyses show a surge in words that resonate with several indicators of scientificity (dimensions of systematicity) and which discursively construct an empiricist, systematic frame. Comparable with the qualities of the scientific method, this frame constitutes a new social scientific method that is not used, but constructed as an approach. Empiricism is both mediates and is mediated by knowledge production not through the direct manipulation of method or even theory use, but by redefining the ways in which methods are being labeled and knowledge framed and remembered. Imagining sociology as a collection of representations extended over time, built upon an empiricist (object) discursive frame mediated by articles (subjects), the social scientific method is becoming embedded in social scientific culture and propelled towards empiricism, discursive compartmentalization, and theoretical compartmentalization. Systematic empiricism, or the culmination of these dimensions, in sociology attempts to organize research according to grand narratives spanning multiple contexts. The effect of this ordering surpasses the article, going so far as to inflict a predictable order upon the way research is conducted and social reality perceived.

The merits of this essentially deductive approach are questionable. On the one hand, it implies the promise of a more connected, cohesive community of social researchers beginning the road to much needed concerted intellectual action in a wildly fragmenting modernity. But on the other, it possesses the perils of every deductive approach: foreclosing the possibilities of understanding phenomena beyond what is predetermined, wherein the only promise of flexibility or induction that remains is the slight re-purposing of the original categories to accommodate for "anomalies" (Kuhn 1962; Popper 1963; Lakatos 1978); at its core, neglecting potentially promising observations (Adorno 1998:28, 32-4). And as the social scientific method extents to even qualitative methods, the recursivity central to verifying the quality of social research - the shuttling between the use of predefined coding categories for analysis 
and developing newly identified codes for analysis (LeCompte and Schensul 2013) becomes bound to deductive forms, individuals and observations moving about a fluid social reality are fitted into predetermined categories. The contributions made by this article shed light on the layers of reality buried in old debates - quantification and nonquantification - whilst stimulating thought on new ones: will a rigidized research agenda successfully reorganize knowledge and its production in ways that better connect scholars? Has generalizability run its course as a standard for knowledge production under the social scientific method, when pitted against the merits of localization - exploring, addressing, and maximizing on local, present contexts? Having laid out the foreground for these lines of inquiry, this article opens dialogue on their pressing challenges for the future of social research, whose solutions will come by interdisciplinary discussion across and among sociology, methodology, philosophy, and history.

Acknowledgements Thanks are due to Martin Bauer and Flora Cornish, whose comments have enriched this paper as a result.

\section{Compliance with Ethical Standards}

Conflicts of Interest The author declares that there are no conflicts of interest.

\section{Appendix}

Table 2 The frequencies of fifteen most used words in titles and abstracts compared over time (as a proportion of 60 total keywords)

\begin{tabular}{|c|c|c|c|c|c|c|c|}
\hline \multirow[t]{2}{*}{ Word } & \multicolumn{7}{|l|}{ Year } \\
\hline & 1950 & 1960 & 1970 & 1980 & 1990 & 2000 & 2010 \\
\hline Research & $7.89 \%$ & $5.84 \%$ & $4.69 \%$ & $6.12 \%$ & $2.02 \%$ & $4.95 \%$ & $5.56 \%$ \\
\hline Data & $5.26 \%$ & $4.38 \%$ & $5.08 \%$ & $5.44 \%$ & $2.42 \%$ & $4.05 \%$ & $7.04 \%$ \\
\hline Study & $10.53 \%$ & $2.19 \%$ & $5.08 \%$ & $2.72 \%$ & $1.61 \%$ & $4.50 \%$ & $7.04 \%$ \\
\hline Theory & & $6.57 \%$ & $4.69 \%$ & $4.42 \%$ & $6.45 \%$ & $1.80 \%$ & $2.59 \%$ \\
\hline Analysis & $15.79 \%$ & $0.73 \%$ & $3.13 \%$ & $4.08 \%$ & $4.84 \%$ & $4.95 \%$ & $2.96 \%$ \\
\hline Effects & & $5.11 \%$ & $1.95 \%$ & $1.02 \%$ & $3.63 \%$ & $5.86 \%$ & $5.56 \%$ \\
\hline Model & & & $3.52 \%$ & $4.76 \%$ & $2.42 \%$ & $5.41 \%$ & $1.85 \%$ \\
\hline Findings & $5.26 \%$ & $2.92 \%$ & $1.95 \%$ & $4.76 \%$ & $1.21 \%$ & $2.70 \%$ & $4.07 \%$ \\
\hline Support & & $2.92 \%$ & $1.17 \%$ & $3.06 \%$ & $4.84 \%$ & $2.25 \%$ & $2.96 \%$ \\
\hline Structure & & $8.03 \%$ & $1.17 \%$ & $2.72 \%$ & $3.23 \%$ & $1.80 \%$ & $1.85 \%$ \\
\hline Results & & & $1.56 \%$ & $3.06 \%$ & $3.63 \%$ & $3.60 \%$ & $2.96 \%$ \\
\hline Differences & $2.63 \%$ & $1.46 \%$ & $1.17 \%$ & $2.72 \%$ & $2.82 \%$ & $5.41 \%$ & $1.48 \%$ \\
\hline System & & $7.30 \%$ & $1.56 \%$ & $1.36 \%$ & $1.61 \%$ & $2.70 \%$ & $3.33 \%$ \\
\hline Rates & & & $3.52 \%$ & $1.36 \%$ & $2.82 \%$ & $4.05 \%$ & $2.22 \%$ \\
\hline Effect & & $1.46 \%$ & $1.17 \%$ & $1.70 \%$ & $4.44 \%$ & $1.35 \%$ & $3.70 \%$ \\
\hline
\end{tabular}


Table 3 Wordstat categorization dictionary for hierarchical cluster analysis

Analyses, evidence, hypotheses (39)

Analyses

Analysis

Data

Differences ${ }^{1}$

Effect

Effects

Empirical

Evidence

Explanations

Factors

\section{Findings}

Hypotheses

Hypothesis

Impact

Implications

Level

Levels

Measures

Model

Models

External reference (5)

Differential

Literature

Policy

Relations

Structures

System (3)

Pattern

System

Systems

Leftover words (2)

Matching

Relations
Outcomes

Patterns

Rates

Relationship

Research

Results

Sample

Significant

Structure

Studies

Study

Support

Terms

Tested

Test

Tests

Theoretical

Theories

Theory

Examination \& measurement (8)

Control

Distribution

Examined

Identification

Measure

Rate

Relationships

Variables

Structure \& function (3)

Function

Interaction

Structural

Bolded are the fifteen most frequently used words (from Fig. 1) 
Open Access This article is distributed under the terms of the Creative Commons Attribution 4.0 International License (http://creativecommons.org/licenses/by/4.0/), which permits unrestricted use, distribution, and reproduction in any medium, provided you give appropriate credit to the original author(s) and the source, provide a link to the Creative Commons license, and indicate if changes were made.

\section{References}

Abbott, A. (2001). Chaos of disciplines. Chicago: University of Chicago Press.

Abbott, A. (2012). Comment on Richard Swedberg: Surprise! Some comments on Richard Swedberg's Peirce paper. Sociologica, 2, 1-4.

Adkins, D., \& Budd, J. (2006). Scholarly productivity of U.S. LIS faculty. Library and Information Science Research, 28(3), 374-389.

Adorno, T. (1998). Critical models: Interventions and catchwords. Translated by H. Pickford. New York: Columbia University Press.

Babones, S. (2016). Interpretive quantitative methods for the social sciences. Sociology, 50(3), 453-469.

Bauer, M. (2001). Classical content analysis. In M. Bauer \& G. Gaskell (Eds.), Qualitative researching with text, image, and sound (pp. 131-151). London: Sage.

Bauer, M., \& Gaskell, G. (1999). Towards a new paradigm for research on social representations. Journal for Theory of Social Behavior, 29(2), 163-186.

Bauer, M., \& Gaskell, G. (2008). Social representations theory: A progressive research Programme for social Psychology. Journal for Theory of Social Behavior, 38(4), 335-353.

Becker, H. S. (1998). Tricks of the trade: How to think about your research while You're doing it. Chicago: University of Chicago Press.

Becker, H. S. (2014). What about Mozart? What about murder? Reasoning from cases. Chicago: University of Chicago Press.

Benoit, K. (2015). The challenge of Big Data for the social sciences. Resource document. London School of Economics. http://www.1se.ac.uk/website-archive/newsAndMedia/videoAndAudio/channels /publicLecturesAndEvents/player.aspx?id=2888. Accessed 18 January 2017.

Bertilsson, M. (2016). Theorizing - For what? British Journal of Sociology, 67(1), 30-35.

Blau, P. (1967). Exchange and power in social life. New York: Wiley.

Blumer, H. (1962). Society and symbolic interaction. In A. M. Rose (Ed.), Human behavior and social process. Boston: Houghton Mifflin.

Bourdieu, P. (1988). Homo Academicus, translated by Peter collier. Stanford: Stanford University Press.

Bunge, M. (1999). The sociology-philosophy connection. New Brunswick: Transaction.

Burrows, R., \& Savage, M. (2014). After the crisis? Big data and the methodological challenges of empirical sociology. Big Data \& Society, 1, 1-6.

Byrne, D. (2012). UK sociology and quantitative methods: Are we as weak as they think? Or are they barking up the wrong tree? Sociology, 46(1), 13-24.

Calhoun, C. (2007). Sociology in America: A history. Chicago: University of Chicago Press.

Coser, L. A. (1956). The functions of social conflict. New York: The Free Press.

Cronin, B., Snyder, H., \& Atkins, H. (1997). Comparative citation Rankings of authors in monographic and journal literature: A study of sociology. Journal of Documentation, 53(3), 263-273.

Dahrendorf, R. (1959). Class and conflict in industrial Society. Palto Alto: Stanford University Press.

Frickel, S., \& Gross, N. (2005). A general theory of scientific/intellectual movements. American Sociological Review, 70(2), 204-232.

Goffman, E. (1959). The presentation of self in everyday life. New York: Doubleday Anchor Books.

Goode, W. J. (1960). Encroachment, charlatanism, and the emerging profession: Psychology, sociology, and medicine. American Sociological Review, 25(6), 902-965.

Gross, N. (2007). Pragmatism, phenomenology, and twentieth-century American sociology. In C. Calhoun (Ed.), Sociology in America: A history. Chicago: University of Chicago Press.

Hanson, B. (2008). Wither qualitative/quantitative?: Grounds for methodological convergence. Quality \& Quantity, 42(1), 97-111.

Homans, G. (1962). Sentiments and activities. New York: The Free Press.

Horowitz, I. L. (1994). The decomposition of sociology. New York: Oxford University Press. 
Howard, R. L. (1981). A social history of American family sociology, 1865-1940. Westport, Connecticut: Greenwood Press.

Hoyningen-Huene, P. (2008). Systematicity: The nature of science. Philosophia, 36, 167-180.

Husserl, E. (1965). Philosophy as rigorous science. In translated by Q. Lauer Phenomenology and the crisis of philosophy. New York: Harper Torchbooks.

Iliev, R., \& Axelrod, R. (2016). Does causality matter more now? Increase in the proportion of causal language in English texts. Psychology Science, 27(5), 635-643.

Israel, J., \& Tajfel, H. (1972). The context of social Psychology. London: Academic Press.

Ivinson, G., Davies, B., \& Fitz, J. (2011). Knowledge and identity: Concepts and applications in Bernstein's sociology. London: Routledge.

Jacobs, J. A. (2011). Journal Rankings in Sociology: Using the H Index with Google Scholar. Population Studies Center, University of Pennsylvania, PSC Working Paper Series, PSC 11-0.

Jacobs, J. A. (2016). Journal Rankings in sociology: Using the H index with Google scholar. The American Sociologist, 47(2), 192-224.

Kleinman, D. L. (1995). Politics on the endless frontier: Postwar research policy in the United States. Durham: Duke University Press.

Krause, M. (2016). The meanings of theorizing. British Journal of Sociology, 67(1), 23-29.

Krippendorff, K. (1980). Content analysis: An introduction to its methodology. London: Sage.

Kuhn, T. (1962). The structure f scientific revolutions. Chicago: University of Chicago Press.

Lakatos, I. (1978). The methodology of scientific research programs. Cambridge: Cambridge University Press.

Lecompte, D., \& Schensul, J. J. (2013). Analysis and interpretation of ethnographic data: A mixed methods approach (2nd ed.). Lanham: AltaMira.

Liu, W. T. (1960). The marginal Catholics in the south a revision of concepts. American Journal of Sociology, 65(4), 383-390.

Moscovici, S. (1984). The phenomenon of social representations. In R. Farr \& S. Moscovici (Eds.), Social representations (pp. 3-70). Cambridge: Cambridge University Press.

Nisbet, R. A. (2002[1976]). Sociology as an art form. New Brunswick: Transaction Publishers.

Norenzayan, A., \& Nisbett, R. E. (2000). Culture and causal cognition. Current Directions in Psychological Science, 9, 132-135.

Parsons, T. (1937). The structure of social action. New York: The Free Press.

Penn, D. C., \& Povinelli, D. J. (2007). Causal cognition in human and nonhuman animals: A comparative, critical review. Annual Review of Psychology, 58, 97-118.

Platt, J. (1996). History of sociological research methods in America. Cambridge: Cambridge University Press.

Popper, K. (1963). Conjectures and refutations. London: Routledge and Kegan Paul.

Price, D. H. (2003). Subtle means and enticing carrots: The impact of funding on American cold war anthropology. Critique of Anthropology, 23(4), 373-401.

Riesch, H. (2014). Philosophy, history and sociology of science: Interdisciplinary relations and complex social identities. Studies in History and Philosophy of Science, 48, 30-37.

Rucker, D. (1969). The Chicago pragmatists. Minneapolis: University of Minnesota Press.

Simmel, G. (1950). The sociology of Georg Simmel. Glencoe, IL: The Free Press.

Spiegelberg, H. (1960-1969). The phenomenological movement (Vol. 2 volumes). The Hague: Martinus Nijhoff. Steinmetz, G. (2007). American sociology before and after world war II. In C. Calhoun (Ed.), Sociology in America: A history (pp. 314-366). Chicago: University of Chicago Press.

Swedberg, R. (2016a). Before theory comes theorizing or how to make social science more interesting. British Journal of Sociology, 67(1), 5-22.

Swedberg, R. (2016b). Reply to the commentators. British Journal of Sociology, 67(1), 57-70.

Tavory, I. (2016). The pragmatist wave of theory construction. British Journal of Sociology, 67(1), 50-56.

Turner, S. P., \& Turner, J. H. (1990). The impossible science: An institutional analysis of American sociology. Newbury Park: Sage.

Wax, M. (1960). Ancient Judaism and the Protestant ethic. American Journal of Sociology, 65(5), 449-455.

White Jr., O. F. (1998). The ideology of technocratic empiricism and the discourse movement in contemporary public administration: A clarification. Administration and Society, 30(4), 471-476.

Wilde, M. J., Geraty, K., Nelson, S. L., \& Bowman, E. A. (2010). Religious economy or organizational field? Predicting bishops' votes at the Second Vatican Council. American Sociological Review, 75(4), 586-606

Zeitlin, I. (1973). Rethinking sociology. Englewood Cliffs: Prentice-Hall.

Zeitlin, I. (2001). Ideology and the development of sociological theory (7th ed.). Englewood Cliffs: PrenticeHall. 